Int. J. Electrochem. Sci., 11 (2016) $8972-8980$

\title{
Application of Single-Walled Carbon Nanohorn Modified Electrode for the Direct Electrochemistry of Myoglobin
}

\author{
Lijun Yan, Xueliang Niu, Zuorui Wen, Xiaoyan Li, Xiaobao Li, Wei Sun* \\ Key Laboratory of Tropical Medicinal Plant Chemistry of Ministry of Education, College of \\ Chemistry and Chemical Engineering, Hainan Normal University, Haikou 571158, P. R. China \\ *E-mail: swyy26@ hotmail.com
}

doi: $10.20964 / 2016.11 .02$

Received: 15 July 2016 / Accepted: 10 September 2016 / Published: 10 October 2016

\begin{abstract}
An electrochemical biosensor was fabricated with myoglobin $(\mathrm{Mb})$, single-walled carbon nanohorns (SWCNHs) and carbon ionic liquid electrode (CILE). By applying chitosan (CTS) film on the electrode surface, the modified electrode was constructed and demonstrated as $\mathrm{CTS} / \mathrm{Mb} / \mathrm{SWCNHs} / \mathrm{CILE}$. Spectroscopic data proved that Mb remained the secondary structure within mixture. Cyclic voltammogram of CTS/Mb/SWCNHs/CILE exhibited a pair of well-defined redox peaks, showing that direct electron transfer of Mb with CILE was realized due to the acceleration effect of SWCNHs. The bioelectrode displayed excellent electrocatalytic behaviors to the reduction of tricholoacetric acid and $\mathrm{NaNO}_{2}$.
\end{abstract}

Keywords: Direct electrochemistry. electrocatalysis. single-walled carbon nanohorns. myoglobin. carbon ionic liquid electrode

\section{$\underline{\text { FULL TEXT }}$}

(C) 2016 The Authors. Published by ESG (www.electrochemsci.org). This article is an open access article distributed under the terms and conditions of the Creative Commons Attribution license (http://creativecommons.org/licenses/by/4.0/). 